\title{
cma]OPEN
}

\section{Burnout and distress among physicians in a cardiovascular centre of a quaternary hospital network: a cross-sectional survey}

\author{
Barry Rubin MD PhD, Rebecca Goldfarb PhD, Daniel Satele MSc, Leanna Graham MHSc
}

See related research articles at www.cmajopen.ca/lookup/doi/10.9778/cmajo.20200058 and www.cmajopen.ca/lookup/doi/10.9778/cmajo.20200059

\section{Abstract}

Background: Burnout and distress have a negative impact on physicians and the treatment they provide. Our aim was to measure the prevalence of burnout and distress among physicians in a cardiovascular centre of a quaternary hospital network in Canada, and compare these outcomes to those for physicians at academic health science centres (AHSCs) in the United States.

Methods: We conducted a survey of physicians practising in a cardiovascular centre at 2 quaternary referral hospitals in Toronto, Ontario, between Nov. 27, 2018, and Jan. 31, 2019. The survey tool included the Well-Being Index (WBI), which measures fatigue, depression, burnout, anxiety or stress, mental and physical quality of life, work-life integration, meaning in work and distress; a score of 3 or higher indicated high distress. We also evaluated physicians' perception of the adequacy of staffing levels and of fair treatment in the workplace, and satisfaction with the electronic health record. We carried out standard univariate statistical comparisons using the $\chi^{2}$, Fisher exact or Kruskal-Wallis test as appropriate to perform univariate comparisons in the sample of respondents. We assessed the relation between a WBI score of 3 or higher and demographic characteristics. We compared univariate associations among WBI data for physicians at AHSCs in the US who completed the WBI to responses from our participants.

Results: The response rate to the survey was $84.1 \%(127 / 151)$. Of the 127 respondents, $83(65.4 \%)$ reported burnout in the previous month, and 68 (53.5\%) reported emotional problems. Sixty-nine respondents (54.3\%) had a WBI score of 3 or higher. Respondents were more likely to have a WBI score of 3 or higher versus a score less than 3 if they perceived insufficient staffing levels (52/69 [75\%] v. $26 / 58$ [45\%], $p=0.02)$ or unfair treatment $(23 / 69$ [33\%] v. $8 / 58[14 \%], p=0.03)$, or were anesthesiologists $(26 / 35[74 \%]$ v. $43 / 92$ [47\%] for other specialists, $p=0.005)$. Compared to 21594 physicians in practice at AHSCs in the US, our respondents had a higher mean WBI score (2.4 v. 1.8, $p=0.004)$ and reported a higher prevalence of burnout $(65.4 \% \mathrm{v} .56 .6 \%, p=0.048)$.

Interpretation: Physicians in this study had high levels of burnout and distress, driven by the perception of inadequate staffing levels and being treated unfairly in the workplace. Addressing these institutional factors may improve physicians' work experience and patient outcomes.

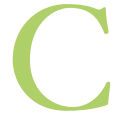
linician burnout is a work-related syndrome characterized by emotional exhaustion, a sense of reduced personal accomplishment, and depersonalization that may manifest as negativity, cynicism and the inability to express empathy or grief. ${ }^{1,2}$ Burnout among physicians is associated with decreased quality of life, high fatigue, increased job turnover and suicidal ideation..$^{3-5}$ Burnout also adversely affects the quality of care that physicians provide, and correlates with an increased risk of medical errors, serious safety events and malpractice proceedings, as well as reduced patient satisfaction and worse patient outcomes, including health care-associated infections. ${ }^{3,4,6-9}$ Health care workers are at high risk for mental health issues, including anxiety, depression and suicide. ${ }^{10,11}$ In addition, burnout has a substantial negative economic impact on health care systems owing to reduced clinical hours and the costs associated with physician turnover. ${ }^{12}$

Nearly half of all physicians experience burnout in some form, a rate more than twice that among professionals in other fields. ${ }^{2,5}$ In addition to burnout, clinically relevant

Competing interests: None declared.

This article has been peer reviewed.

Correspondence to: Barry Rubin, Barry.Rubin@uhn.ca

CMAJ Open 2021. DOI:10.9778/cmajo.20200057 
dimensions of distress include meaning in work, severe fatigue, work-life integration, quality of life and suicidal ideation. ${ }^{13}$ The high prevalence of physician burnout and overall distress constitutes a public health crisis. ${ }^{2,14,15}$

Drivers of physician burnout include excessive workloads, inefficient work processes, clerical burden, work-home conflicts, and lack of input or control over issues affecting their work lives, organizational support structures and leadership culture. ${ }^{16}$ Individual physician-level factors also play a role, with higher rates of burnout reported among female physicians, ${ }^{16}$ younger physicians ${ }^{16}$ and minority ethnic groups compared to non-Hispanic White physicians. ${ }^{17}$

The aim of this research was to measure the prevalence of burnout and distress among physicians practising in a cardiovascular centre at 2 quaternary referral hospitals within a single-payer public health care system environment. We also compared the prevalence of burnout and distress between this group and physicians in practice in the United States at academic health science centres (AHSCs), defined as complex organizations with a tripartite mission of delivering highquality research, medical education and clinical care. ${ }^{18}$

\section{Methods}

\section{Design, setting and recruitment}

We conducted a survey at the Peter Munk Cardiac Centre (PMCC), which is the cardiovascular centre for the University Health Network in Toronto, Ontario. It is based at 2 quaternary referral hospitals: Toronto General Hospital and Toronto Western Hospital. The survey was open to all PMCC physicians and was conducted between Nov. 27, 2018, and Jan. 31, 2019.

Posters describing the survey were placed in multiple areas across the 2 sites (Appendix 1, available at www.cmajopen.ca/ content/9/1/E10/suppl/DC1). An independent third party (Canadian Viewpoint, https://canview.com/) sent an initial email invitation (Appendix 2, available at www.cmajopen.ca/ content/9/1/E10/suppl/DC1) and subsequent reminders to complete the survey to all physicians practising in the PMCC. Neither the University Health Network nor the authors had access to individual responses to the survey, which were collected by Corporate Web Services (https://www.cws.net/).

\section{Survey tool development}

Multiple surveys can be used to assess burnout, well-being and other work-related dimensions of distress, including the Maslach Burnout Inventory - Human Services Survey for Medical Personnel, ${ }^{1,2,19}$ the Oldenburg Burnout Inventory, the single-item measure used in the Physician Worklife Study, the Copenhagen Burnout Inventory, the Stanford Professional Fulfillment Index, the Well-Being Index $(\mathrm{WBI})^{13,20}$ and the Patient Health Questionnaire-9 of the self-report component of the Primary Care Evaluation of Mental Disorders inventory. The validity and reliability of these survey instruments, including consideration of the format, source of data, development and testing, links to outcomes or health system characteristics related to health care professionals, past or validated applications, and cost, have been reported..$^{21}$

After reviewing these validated survey instruments, we chose to use the WBI because it has a core of only 9 questions, takes minutes to complete, provides instantaneous and confidential feedback to survey participants, and has been independently validated for use in a diverse group of health care professionals, including physicians, nurses and nonphysician employees. ${ }^{13,20,22}$ Use of the WBI also enabled comparison of our results to a large group of physicians in the US, in whom a WBI score of 3 or higher identified those with high levels of overall distress. ${ }^{13}$ The WBI can also identify physicians who are doing well (high overall quality of life, high degree of meaning in work, satisfied with work-life balance) and those whose degree of distress increases the risk of adverse professional consequences. ${ }^{13}$

Seven of the $9 \mathrm{WBI}$ items are questions that are answered "Yes" or "No," with 1 point assigned for each "Yes" response.

Responses to the statement "The work I do is meaningful to me" were based on the Empowerment at Work Scale ${ }^{23}$ (7-point Likert scale where $1=$ very strongly disagree and $7=$ very strongly agree). Respondents who indicated 1 or 2 on the Likert scale had 1 point added to their score, and those who indicated 6 or 7 on the Likert scale had 1 point subtracted from their score.

Respondents indicated their level of agreement with the statement "My work schedule leaves me enough time for my personal/family life" on a 5-point Likert scale where $1=$ strongly disagree and 5 = strongly agree. Respondents who indicated lower satisfaction with work-life integration (i.e., 1 or 2 on the Likert scale) had 1 point added to their score, and those who indicated higher satisfaction (i.e., 4 or 5 on the Likert scale) had 1 point subtracted from their score.

Accordingly, the total score for the WBI ranged from -2 to 9 .

We also asked survey participants to supply demographic information and respond to 3 additional statements designed to assess work culture ("Please rate your satisfaction with your electronic health record," 24 "The staffing levels in this work setting are sufficient to handle the number of patients" and "I am treated fairly in the workplace"). Respondents indicated their level of agreement with the 3 statements on a 5-point Likert scale where 1 = strongly disagree and $5=$ strongly agree. The full survey tool is presented in Appendix 3 (available at www.cmajopen.ca/content/9/1/E10/suppl/DC1).

\section{Feedback}

On completion of the survey, physicians received instantaneous feedback via email in the form of a dashboard from the survey administrator (Corporate Web Services) that quantified each dimension of distress. If a WBI score indicative of high distress (i.e., $\geq 3^{13}$ ) was identified, the email response to individual study participants included the information required to access local, regional and provincial resources that provide assistance managing stress and resilience, fatigue, emotional concerns, suicidal thoughts, issues related to relationships and work-life balance, and alcohol or substance abuse. 


\section{Statistical analysis}

We evaluated the relation between physicians' responses to individual WBI survey questions and participants' gender, years in practice, area of practice, satisfaction with the hospital's electronic health record, perception of the adequacy of staffing levels, perception of being treated fairly in the workplace, work-life integration and meaning in work. We assessed demographic and environmental factors that predicted high WBI scores, and compared physicians' responses to WBI scores of physicians in practice at AHSCs in the US. ${ }^{13} \mathrm{We}$ also recorded the number of times respondents accessed contact information for local, regional or provincial resources after they received feedback.

We carried out standard univariate statistical comparisons using the $\chi^{2}$ test when expected counts were 5 or greater, the Fisher exact test when expected counts were less than 5 and the Kruskal-Wallis test for nonparametric continuous variables to perform univariate comparisons in the sample of respondents. We assessed the relation between selected demographic and work culture items and responses to elements of the survey, both between and within groups. We also assessed the relation between a WBI score of 3 or higher and demographic characteristics, as well as responses to statements about work culture. Finally, we compared univariate associations among WBI data for physicians in practice at AHSCs in the US ${ }^{13}$ with responses from our respondents. We conducted all analyses using SAS Version 9 (SAS Institute).

\section{Ethics approval}

The University Health Network Research Ethics Board provided a waiver for the requirement for research ethics approval for this study (waiver 18-0246).

\section{Results}

Of the 151 physicians invited to participate in the survey, 127 $(84.1 \%)$ responded. We report the respondents' gender, years since graduation from medical school, years working at University Health Network and medical specialty in Table 1.

The mean WBI score was 2.4 (standard deviation [SD] 2.6). The distribution of WBI scores is shown in Figure 1.

Eighty-three respondents (65.4\%) indicated that, in the previous month, they felt burned out from their work, 68 $(53.5 \%)$ reported that they had been bothered by emotional problems, $63(49.6 \%)$ reported that things were piling up so high they could not overcome them, and 61 (48.0\%) indicated that work was hardening them emotionally; about 1 in 5 (26 [20.5\%]) agreed or strongly agreed that their work schedule left them enough time for their personal life. More than three-quarters (99 [78.0\%]) strongly or very strongly agreed that the work they did was meaningful to them. Responses to the remaining survey questions are presented in Appendix 4 (available at www.cmajopen.ca/content/9/1/E10/suppl/DC1).

Thirty-four (28.6\%) of 119 respondents agreed or strongly agreed that staffing levels were adequate. Compared to those respondents, the 85 physicians $(71.4 \%)$ who were neutral or somewhat or strongly disagreed that staffing levels were adequate were more likely to report feeling burned out from their

\begin{tabular}{|lc|}
\hline $\begin{array}{l}\text { Table 1: Characteristics of physicians who responded to the } \\
\text { Well-Being Index survey }\end{array}$ & $\begin{array}{c}\text { No. (\%) of respondents } \\
n=127\end{array}$ \\
\hline & \\
\hline Characteristic & $90(70.9)$ \\
\hline Gender & $36(28.3)$ \\
\hline Male & $1(0.8)$ \\
\hline Female & $3(2.4)$ \\
\hline Missing & $14(11.0)$ \\
\hline Time since graduation, yr & $19(15.0)$ \\
\hline $2-5$ & $91(71.6)$ \\
\hline $6-10$ & \\
\hline $11-15$ & $18(14.2)$ \\
\hline$>15$ & $21(16.5)$ \\
\hline Time working at University Health & $23(18.1)$ \\
\hline Network, yr & $24(18.9)$ \\
\hline$<2$ & $41(32.3)$ \\
\hline $2-5$ & $35(27.6)$ \\
\hline $6-10$ & $4(3.1)$ \\
\hline $11-15$ & $10(7.9)$ \\
\hline$>15$ & \\
\hline Specialty & \\
\hline Anesthesia & \\
\hline Cardiac rehabilitation & \\
\hline Cardiac surgery & \\
\hline Cardiology & \\
\hline Medical imaging & \\
\hline Vascular surgery & \\
\hline Other & \\
\hline
\end{tabular}

work $(65[77.5 \%]$ v. $16[47.1 \%], p=0.002)$, to worry that work was hardening them emotionally $(51[60.0 \%]$ v. $10[29.4 \%], p=$ $0.003)$, to feel that things were piling up so high that they could not overcome them (52 [61.2\%) v. 9 [26.5\%], $p=0.006)$ and to disagree that their work schedule left them enough time for their personal life (57 [61.1\%] v. 14 [41.2\%], $p=0.02)$.

Seventy-three $(61.3 \%)$ of 119 respondents agreed or strongly agreed that they were treated fairly in the workplace. Compared to those respondents, the 46 physicians (38.7\%) who were neutral or somewhat or strongly disagreed that they were treated fairly in the workplace were more likely to worry that work was hardening them emotionally (30 [65\%] v. 31 [43\%], $p=0.02)$, to feel down, depressed or hopeless (22 [48\%] v. $15[21 \%], p=0.002$ ) and to report being bothered by emotional problems (31 [67\%] v. $34[47 \%], p=0.03$ ); they were also less likely to report that the work they did was meaningful to them (30 [65\%] v. $61[84 \%], p=0.03)$.

Anesthesiologists were more likely than other physicians to report being worried that work was hardening them emotionally $(25 / 35[71 \%]$ v. 36/92 [39\%], $p=0.007)$ and were less likely to somewhat or strongly agree that the work they did was meaningful to them $(21 / 35[60 \%]$ v. $78 / 92$ [85\%], $p=0.02)$. 


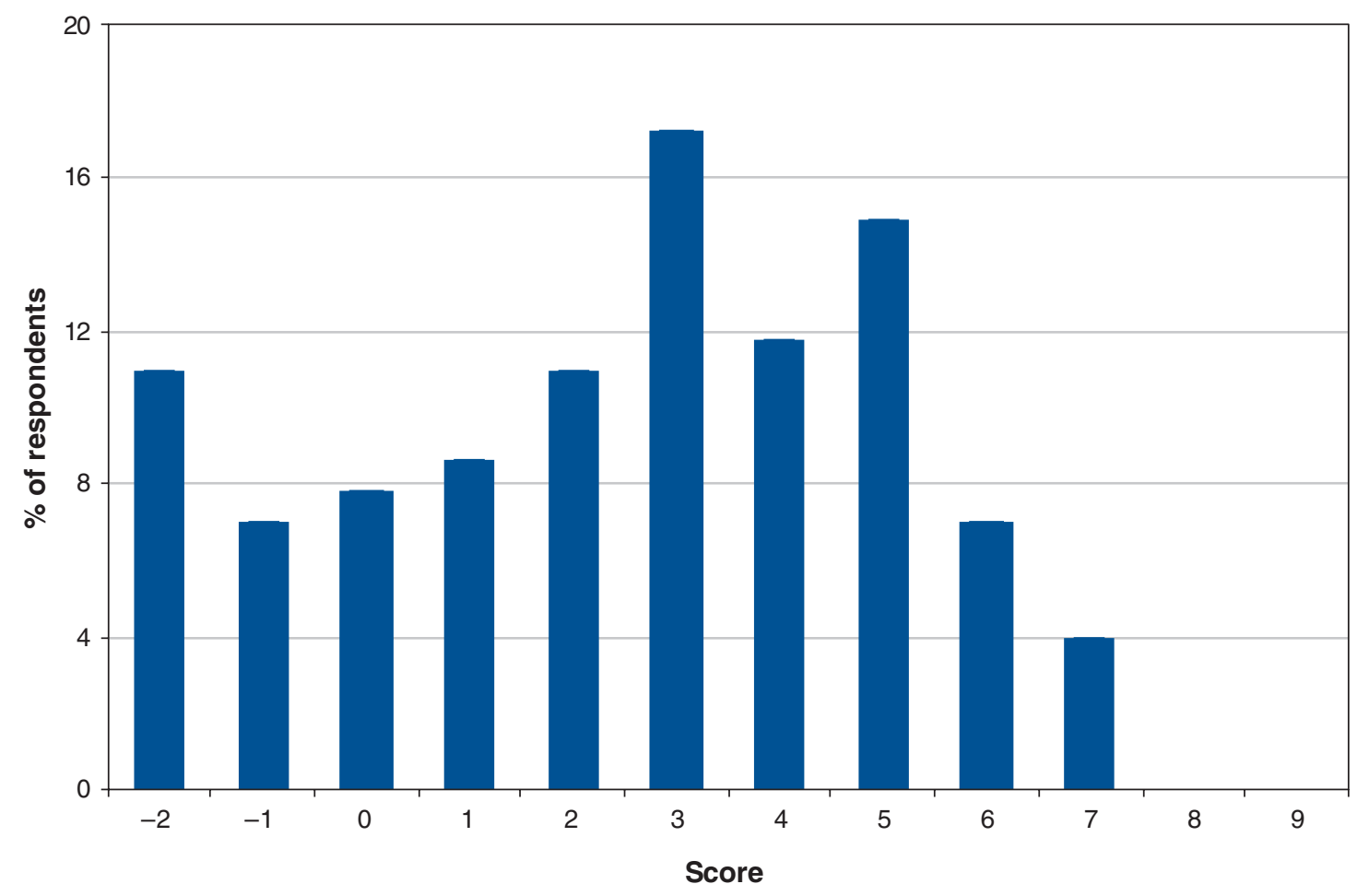

Figure 1: Distribution of Well-Being Index scores among 127 Peter Munk Cardiac Centre physicians.

The number of times physicians accessed contact information for local, regional or provincial resources that provide assistance managing each element of distress is presented in Figure 2.

\section{Predictors of high scores}

Sixty-nine respondents $(54.3 \%)$ had a score of 3 or higher, and $33(26.0 \%)$ had a score of 5 or higher. Respondents were more likely to have a WBI score of 3 or higher versus less than 3 if they somewhat or strongly disagreed that staffing levels were sufficient (52/69 [75\%] v. 26/58 [45\%], $p=0.02)$ (Table 2). Respondents were also more likely to have a WBI score of 3 or higher if they somewhat or strongly disagreed that they were treated fairly in the workplace $(23 / 69[33 \%] \mathrm{v}$. $8 / 58[14 \%], p=0.03)$.

Anesthesiologists were more likely than other physicians to have a WBI score of 3 or higher (26/35 [74\%] v. 43/92 [47\%], $p=0.005)$. We did not identify a relation between the proportion of respondents with a WBI score of 3 or higher and physician gender, years since graduation from medical school, years working at PMCC or satisfaction with the electronic health record.

\section{Comparison with physicians in the United States}

Compared to the 21594 physicians in practice at AHSCs in the US who completed the WBI, ${ }^{13}$ our respondents had a higher mean WBI score (2.4 [SD 2.6] v. 1.8 [SD 2.7], $p=$
$0.004)$, reported a higher prevalence of burnout $(65.4 \% \mathrm{v}$. $56.6 \%, p=0.048$ ), were less likely to agree that their work schedule left them enough time for their personal life (mean rating on 5-point Likert scale 2.6 [SD 1.1] v. 3.0 [SD 1.2] , $p<$ $0.001)$ and were more likely to be male $(70.9 \%$ v. $59.1 \%, p=$ 0.02) (Table 3). In addition, a higher proportion of PMCC physicians had a WBI score of 3 or higher $(54.3 \%$ v. $40.0 \%$, $p=0.001)$ or 5 or higher $(26.0 \%$ v. $18.4 \%, p=0.03)$. Conversely, PMCC physicians were more likely than US physicians to agree or strongly agree that their work was meaningful to them (mean rating on 7-point Likert scale 6.2 [SD 1.1] v. 5.9 [SD 1.2], $p=0.002)$.

\section{Interpretation}

In this survey, $54 \%$ of PMCC physicians had a WBI score of 3 or higher, and $26 \%$ had a score of 5 or higher. Two-thirds $(65 \%)$ indicated that, in the previous month, they felt burned out from their work, just over half (54\%) reported that they had been bothered by emotional problems, half reported that things were piling up so high they could not overcome them, and almost half (48\%) indicated that work was hardening them emotionally; only 1 in 5 agreed or strongly agreed that their work schedule left them enough time for their personal life. The main drivers of high distress levels were the perception of inadequate staffing levels and of being treated unfairly in the workplace. Anesthesiologists had significantly higher WBI scores than other groups of cardiovascular physicians. 


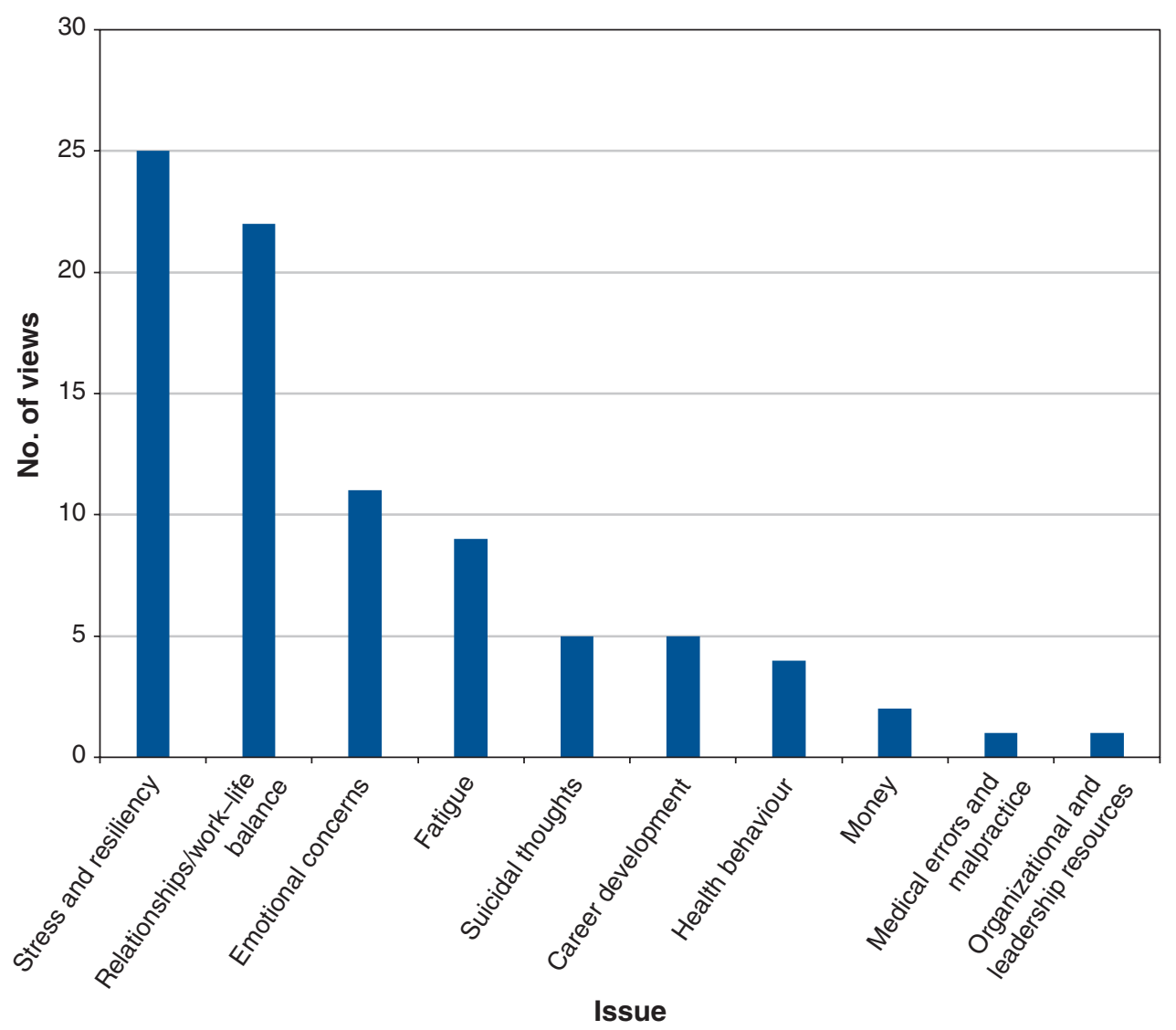

Figure 2: Number of views of online resources by respondents, by issue.

Anesthesiologists were also more likely than other physicians to report that they were worried that their work was hardening them emotionally, and they found their work to be less meaningful than did other physicians.

We used a WBI score of 3 or higher to identify physicians with high levels of overall distress because, in a sample of 6880 physicians, this threshold was associated with a 1.9 -fold higher likelihood of burnout and a 1.4-fold higher likelihood of severe fatigue and poor overall quality of life. ${ }^{13} \mathrm{We}$ considered physicians with a WBI score of 5 or higher to have severe distress because such scores were associated with a higher likelihood of burnout (6.6-fold), poor overall quality of life (3.6fold), severe fatigue (2.9-fold) and suicidal ideation (2.8-fold). ${ }^{13}$

Dissatisfaction with the electronic health record did not correlate with high WBI scores, in contrast to other reports. ${ }^{25,26}$ Our findings are consistent with the recent observation that other factors, including a chaotic work atmosphere, lack of control of workload, time for personal and family life, alignment of values with those of leaders, balance between professional and personal life, and hours worked per week play a more important role in physician burnout than issues related to the electronic health record. ${ }^{27}$ Our finding that time on staff or since graduation from medical school did not affect WBI scores was at odds with the results of the recent Canadian National Physician Health Survey, ${ }^{28}$ which showed that physicians with 5 or fewer years in practice were $45 \%$ more likely to experience burnout than all other physicians.

The Canadian National Physician Health Survey did not identify significant differences in physician burnout according to area of practice, ${ }^{28}$ a finding consistent with our observations (Appendix 4). However, in our study, anesthesiologists were more likely to have a high distress score and were less likely to report finding meaning in work than other physicians. In addition, only $29 \%$ of anesthesiologists agreed that their work schedule left them enough time for their personal life, lower than the proportion of Canadian critical care physicians shown in a national cross-sectional survey, $53 \% .{ }^{29}$ The reasons for a worse provider experience for anesthesiologists than for other groups of physicians in the PMCC is not clear but may relate to working in a high-stress environment, long working hours, insufficient sleep and time pressures; ${ }^{30}$ further evaluation is required.

System-level policy factors may play a role in physician burnout and other dimensions of distress. Our interest in exploring similarities and differences in burnout and distress among physicians between Canada and the US stems in part 


\begin{tabular}{|c|c|c|c|}
\hline \multicolumn{4}{|c|}{$\begin{array}{l}\text { Table } 2 \text { (part } 1 \text { of } 2 \text { ): Predictors of high Well-Being Index } \\
\text { score }(\geq 3)\end{array}$} \\
\hline \multirow[b]{2}{*}{ Variable } & \multicolumn{3}{|c|}{ No. $\left(\%^{*}\right)$ of respondents } \\
\hline & $\begin{array}{c}\text { WBI score } \\
\quad \geq 3 \\
n=69\end{array}$ & $\begin{array}{c}\text { WBI } \\
\text { score }<3 \\
n=58\end{array}$ & $p$ value \\
\hline Gender & & & 0.8 \\
\hline Male & $48(53)$ & $42(47)$ & \\
\hline Female & $20(56)$ & $16(44)$ & \\
\hline Missing & $1(100)$ & $0(0)$ & \\
\hline Time since graduation, yr & & & 0.2 \\
\hline $2-5$ & $3(100)$ & $0(0)$ & \\
\hline $6-10$ & $9(64)$ & $5(36)$ & \\
\hline $11-15$ & $12(63)$ & $7(37)$ & \\
\hline$>15$ & $45(49)$ & $46(50)$ & \\
\hline $\begin{array}{l}\text { Time working at } \\
\text { University Health } \\
\text { Network, yr }\end{array}$ & & & 0.3 \\
\hline$<2$ & $10(56)$ & $8(44)$ & \\
\hline $2-5$ & $15(71)$ & $6(29)$ & \\
\hline $6-10$ & $14(61)$ & 9 (39) & \\
\hline $11-15$ & $11(46)$ & $13(54)$ & \\
\hline$>15$ & $19(46)$ & $22(54)$ & \\
\hline Specialty & & & 0.01 \\
\hline Anesthesia & $26(74)$ & $9(26)$ & \\
\hline Cardiac rehabilitation & $1(25)$ & $3(75)$ & \\
\hline Cardiac surgery & $6(60)$ & $4(40)$ & \\
\hline Cardiology & $24(44)$ & $30(56)$ & \\
\hline Medical imaging & $4(29)$ & $10(71)$ & \\
\hline Vascular surgery & $6(75)$ & $2(25)$ & \\
\hline Other & $2(100)$ & $0(0)$ & \\
\hline Specialty & & & 0.005 \\
\hline Anesthesia & $26(74)$ & $9(26)$ & \\
\hline All others & $43(47)$ & $49(53)$ & \\
\hline $\begin{array}{l}\text { Satisfaction with } \\
\text { electronic health record }\end{array}$ & & & 0.3 \\
\hline Very unsatisfied & $16(76)$ & $5(24)$ & \\
\hline Somewhat unsatisfied & $10(45)$ & $12(54)$ & \\
\hline Neutral & $11(50)$ & $11(50)$ & \\
\hline Somewhat satisfied & $26(59)$ & $18(41)$ & \\
\hline Very satisfied & $5(50)$ & $5(50)$ & \\
\hline Missing & $1(12)$ & $7(88)$ & \\
\hline $\begin{array}{l}\text { Staffing levels in work } \\
\text { setting are sufficient }\end{array}$ & & & 0.02 \\
\hline Disagree strongly & $28(78)$ & $8(22)$ & \\
\hline Disagree somewhat & $24(57)$ & $18(43)$ & \\
\hline Neutral & $3(43)$ & $4(57)$ & \\
\hline Agree somewhat & $8(42)$ & $11(58)$ & \\
\hline Agree strongly & $5(33)$ & $10(67)$ & \\
\hline Missing & $1(12)$ & $7(88)$ & \\
\hline
\end{tabular}

\begin{tabular}{|c|c|c|c|}
\hline $\begin{array}{l}\text { Table } 2 \text { (part } 2 \text { of } 2 \text { ): Predi } \\
\text { score }(\geq 3)\end{array}$ & ors of high & Il-Being & \\
\hline \multirow[b]{2}{*}{ Variable } & \multicolumn{2}{|c|}{ No. $(\%)$ of respondents } & \multirow[b]{2}{*}{$p$ value } \\
\hline & $\begin{array}{c}\text { WBI score } \\
\geq 3 \\
n=69\end{array}$ & $\begin{array}{c}\text { WBI } \\
\text { score }<3 \\
n=58\end{array}$ & \\
\hline Treated fairly in workplace & & & 0.03 \\
\hline Disagree strongly & $8(80)$ & $2(20)$ & \\
\hline Disagree somewhat & $15(71)$ & $6(29)$ & \\
\hline Neutral & $9(60)$ & $6(40)$ & \\
\hline Agree somewhat & $26(60)$ & $17(40)$ & \\
\hline Agree strongly & $10(33)$ & $20(67)$ & \\
\hline Missing & $1(12)$ & $7(88)$ & \\
\hline
\end{tabular}

from the fact that the 2 countries have very different health care systems. Despite these differences, we had postulated that physician levels of burnout and distress would be similar in the 2 settings, as issues inherent to health care work in these different settings would likely drive physician burnout.

Compared to physicians in practice at AHSCs in the US, ${ }^{13}$ PMCC physicians had a higher prevalence of burnout and higher overall WBI scores, and a higher proportion had WBI scores consistent with high or severe distress. The reasons for these unexpected results are not clear, but they may be due to higher physician burnout and distress rates at the PMCC than at other AHSCs in our regional environment. However, this is not supported by the results of the faculty survey conducted by the Department of Medicine at the University of Toronto in 2019, which included the 10 AHSCs in the Greater Toronto Area: when asked how often they felt burned out in the previous 12 months, 18\% (54/301) of respondents at the Toronto General Hospital and Toronto Western Hospital, and 17\% $(192 / 1121)$ of those at the other 8 AHSCs answered "Almost always/daily" or "Almost always" (Dr. Lynn Wilson, Vice Dean, Partnerships, Faculty of Medicine, University of Toronto: personal communication, 2020).

Another possible explanation for the higher burnout rates and overall distress scores among PMCC physicians than among US physicians may relate to intrinsic differences in the health care systems in Canada and the US. For example, although the number of physicians per 1000 population (2.48 v. 2.55$)$ and hospital beds per 10000 population (27 v. 28) in the Canadian and US health care systems are similar, substantially more physicians in the US than in Canada are specialists $(88 \%$ v. $53 \%)$, and the average specialist physician income is higher in the US than in Canada (\$265 000 v. \$230 292). ${ }^{31}$

Challenges related to differences in the volume of patients requiring management may also partially explain the observed disparities in the prevalence of burnout and overall distress scores. A 2018 report showed that the proportions of patients who reported difficulty accessing after-hours care (64\% v. 51\%), waiting more than 2 months for a specialist 


\section{Research}

appointment (30\% v. 6\%) and waiting more than 4 months for elective surgery $(18 \%$ v. $4 \%)$ were all higher in Canada than in the US. ${ }^{31}$ In addition, the percent occupancy of acute care beds is consistently higher in Canada than in the US (91\% v. $64 \%$ in $2000,92 \%$ v. $63 \%$ in 2015). ${ }^{32}$ Longer wait times owing to limitations of resources, less availability of specialist physicians,

\begin{tabular}{|c|c|c|c|}
\hline \multirow[b]{2}{*}{ Item } & \multicolumn{2}{|c|}{ No. $(\%)$ of respondents* } & \multirow[b]{2}{*}{$p$ value } \\
\hline & $\begin{array}{c}\text { PMCC physicians } \\
n=127\end{array}$ & $\begin{array}{l}\text { US physicians } \\
n=21594\end{array}$ & \\
\hline Gender & & & $0.02 \S$ \\
\hline Male & $90(70.9)$ & $12772(59.1)$ & \\
\hline Female & $36(28.3)$ & $8787(40.7)$ & \\
\hline Gender diverse & $0(0.0)$ & $23(0.1)$ & \\
\hline Missing & $1(0.8)$ & $12(0.1)$ & \\
\hline Have you felt burned out from your work? & & & $0.048 \S$ \\
\hline Yes & $83(65.4)$ & $12233(56.6)$ & \\
\hline No & $44(34.6)$ & $9361(43.4)$ & \\
\hline $\begin{array}{l}\text { Have you worried that work is hardening } \\
\text { you emotionally? }\end{array}$ & & & $0.2 \S$ \\
\hline Yes & $61(48.0)$ & $9191(42.6)$ & \\
\hline No & $66(52.0)$ & $12403(57.4)$ & \\
\hline $\begin{array}{l}\text { Have you often felt bothered by feeling } \\
\text { down, depressed or hopeless? }\end{array}$ & & & $0.9 \S$ \\
\hline Yes & $37(29.1)$ & $6200(28.7)$ & \\
\hline No & $90(70.9)$ & $15394(71.3)$ & \\
\hline $\begin{array}{l}\text { Have you fallen asleep while sitting } \\
\text { inactive in a public place? }\end{array}$ & & & $0.2 \S$ \\
\hline Yes & $25(19.7)$ & $3400(15.7)$ & \\
\hline No & $102(80.3)$ & $18194(84.2)$ & \\
\hline $\begin{array}{l}\text { Have you felt that all things you had to do } \\
\text { were piling up so high that you could not } \\
\text { overcome them? }\end{array}$ & & & $0.05 \S$ \\
\hline Yes & $64(50.4)$ & $9048(41.9)$ & \\
\hline No & $63(49.6)$ & $12546(58.1)$ & \\
\hline $\begin{array}{l}\text { Have you been bothered by emotional } \\
\text { problems? }\end{array}$ & & & $0.3 \S$ \\
\hline Yes & $68(53.5)$ & $10470(48.5)$ & \\
\hline No & $59(46.5)$ & $11124(51.5)$ & \\
\hline $\begin{array}{l}\text { Has your physical health interfered with } \\
\text { your ability to do your daily work at home } \\
\text { and/or away from home? }\end{array}$ & & & $0.3 \S$ \\
\hline Yes & $22(17.3)$ & $3047(14.1)$ & \\
\hline No & $105(82.7)$ & $18547(85.9)$ & \\
\hline The work I do is meaningful to me & & & $0.002 \rrbracket$ \\
\hline Mean rating $\pm S D$ & $6.2 \pm 1.11$ & $5.9 \pm 1.22$ & \\
\hline Median rating (range) & 7 (2.0 to 7.0$)$ & $6(1.0$ to 7.0$)$ & \\
\hline $\begin{array}{l}\text { My work schedule leaves me enough time } \\
\text { for my personal/family life } \neq\end{array}$ & & & $<0.0019$ \\
\hline Mean rating $\pm S D$ & $2.6 \pm 1.12$ & $3.0 \pm 1.19$ & \\
\hline Median rating (range) & $2(1.0$ to 5.0$)$ & $3(1.0$ to 5.0$)$ & \\
\hline
\end{tabular}




\begin{tabular}{|c|c|c|c|}
\hline \multirow[b]{2}{*}{ Item } & \multicolumn{2}{|c|}{ No. $(\%)$ of respondents* } & \multirow[b]{2}{*}{$p$ value } \\
\hline & $\begin{array}{c}\text { PMCC physicians } \\
n=127\end{array}$ & $\begin{array}{l}\text { US physicians } \\
n=21594\end{array}$ & \\
\hline WBI score & & & $0.004 \eta$ \\
\hline Mean \pm SD & $2.4 \pm 2.60$ & $1.8 \pm 2.67$ & \\
\hline Median (range) & $3(-2.0$ to 7.0$)$ & $2(-2.0$ to 9.0$)$ & \\
\hline WBI score $\geq 3$ & & & $0.001 \rrbracket$ \\
\hline Yes & $69(54.3)$ & $8641(40.0)$ & \\
\hline No & $58(45.7)$ & $12953(60.0)$ & \\
\hline WBI score $\geq 5$ & & & $0.03 \rrbracket$ \\
\hline Yes & $33(26.0)$ & 3977 (18.4) & \\
\hline No & $94(74.0)$ & $17617(81.6)$ & \\
\hline \multicolumn{4}{|c|}{$\begin{array}{l}\text { Note: PMCC = Peter Munk Cardiac Centre, SD = standard deviation. } \\
\text { *Except where noted otherwise. } \\
\text { †Rated on a } 7 \text {-point Likert scale where } 1=\text { very strongly disagree and } 7=\text { very strongly agree. } \\
\text { fRated on a } 5 \text {-point Likert scale where } 1=\text { strongly disagree and } 5=\text { strongly agree. } \\
\$ \chi^{2} \text { test. } \\
\text { qKruskal-Wallis test. }\end{array}$} \\
\hline
\end{tabular}

differences in the volume of clinical activity and workload, more crowded hospital environments and greater personal financial pressures may also have contributed to the observed differences between our respondents and US physicians.

In contrast, our respondents were more likely than physicians in practice at AHSCs in the US to agree that the work they did was meaningful to them. Additional study is required to determine whether differences in the prevalence of burnout, level of distress and meaning in work exist between physicians in practice in Canada and US, and to identify the drivers of any differences.

In addition to physicians, we also evaluated the prevalence of burnout and distress among nurses and allied health care staff in the PMCC. Similar to the results we observed for physicians, nurses reported a higher prevalence of burnout and were more likely to report worrying that work was hardening them emotionally, feeling down, depressed or hopeless, falling asleep while sitting inactive in a public place, feeling that things were piling up so high they could not overcome them, being bothered by emotional problems and feeling that their physical health interfered with their ability to do their daily work. ${ }^{33}$ In addition, a greater proportion of nurses had a WBI score indicative of high or severe distress than nurses in practice at AHSCs in the US who completed the WBI. Although allied health care staff in the PMCC had higher average WBI scores than nonphysician employees in the US who completed the WBI, and higher proportions of PMCC allied health care staff reported burnout and were worried that work was hardening them emotionally, the proportions of PMCC allied health staff and nonphysician employees in the US with WBI scores consistent with high or severe distress were similar. ${ }^{34}$

The observed high prevalence of distress scores above the threshold at which physicians are at risk for mental health issues and for providing suboptimal patient care emphasizes the need to direct efforts and resources toward intervention strategies that have been shown to decrease clinician burnout. ${ }^{16,35-37}$ Multiple interventions have focused on improving the mental health of physicians, including individual-focused approaches such as mindfulness training, stress management, and small-group discussions. ${ }^{35}$ Structural or organizational strategies, such as changes in work schedules, fostering communication between members of health care teams, and cultivating a sense of teamwork and job control,,$^{37,38}$ as well as professional coaching sessions ${ }^{37}$ could also be implemented to decrease physician burnout and distress. The baseline data reported in this survey can be used to plan and assess the impact of these interventions at regular intervals.

\section{Limitations}

The relatively modest number of respondents may limit study validity and makes type 2 statistical errors more likely. It also preluded multivariable analysis of the survey data. The fact that this was a 2-institution study may limit the generalizability of the results. The supplemental survey questions related to perception of the adequacy of staffing levels, fair treatment in the workplace and satisfaction with the electronic health record were not subject to pilot evaluation. Although we cannot exclude the possibility that physicians experiencing burnout may be less likely to complete a survey that could be viewed as additional work, the majority $(85.1 \%)$ of physicians participating in the survey answered all survey questions.

Comparison of the prevalence of burnout and WBI scores between physicians in practice in the PMCC and in AHSCs in the US may have a gender bias, because the proportion of male respondents was relatively higher in our sample than in the US sample. Importantly, our respondents included only 
physicians who practised in the area of cardiovascular medicine and surgery, which may limit the ability to directly compare the prevalence of burnout and distress between our respondents and US physicians, who practised across the full spectrum of specialties.

\section{Conclusion}

The perception of inadequate staffing levels and unfair treatment in the workplace correlated with higher levels of overall distress among physicians in the PMCC. Initiatives that focus on addressing these institutional factors may lower distress levels among PMCC physicians and improve their work experience and patient outcomes.

\section{References}

1. Maslach C, Jackson SE, Leiter MP. Maslach burnout inventory manual. 3rd ed. Palo Alto (CA): Consulting Psychologists Press; 1996.

2. Dzau VJ, Kirch DG, Nasca TJ. To care is human - collectively confronting the clinician-burnout crisis. N Engl F Med 2018;378:312-4.

3. Balch CM, Oreskovich MR, Dyrbye LN, et al. Personal consequences of malpractice lawsuits on American surgeons. 7 Am Coll Surg 2011;213:657-67.

4. Welp A, Meier LL, Manser T. Emotional exhaustion and workload predict clinician-rated and objective patient safety. Front Psychol 2015;5:1573.

5. Shanafelt TD, Boone S, Tan L, et al. Burnout and satisfaction with work-life balance among US physicians relative to the general US population. Arch Intern Med 2012;172:1377-85.

6. Panagioti M, Geraghty K, Johnson J, et al. Association between physician burnout and patient safety, professionalism, and patient satisfaction: a systematic review and meta-analysis. FAMA Intern Med 2018;178:1317-31.

7. Tawfik DS, Profit J, Morgenthaler TI, et al. Physician burnout, well-being, and work unit safety grades in relationship to reported medical errors. Mayo Clin Proc 2018;93:1571-80.

8. Hall LH, Johnson J, Watt I, et al. Healthcare staff wellbeing, burnout, and patient safety: a systematic review. PLoS One 2016;11:e159015.

9. Bakhamis L, Paul DP 3rd, Smith H, et al. Still an epidemic: the burnout syndrome in hospital registered nurses. Health Care Manag (Frederick) 2019;38:3-10.

10. Jollant F, Hawton K, Vaiva G, et al. Non-presentation at hospital following a suicide attempt: a national survey. Psychol Med 2020 July 3 [Epub ahead of print]. doi: 10.1017/S0033291720002305.

11. Dutheil F, Aubert C, Pereira B, et al. Suicide among physicians and health-care workers: a systematic review and meta-analysis. PLoS One 2019;14:e0226361.

12. Han S, Shanafelt TD, Sinsky CA, et al. Estimating the attributable cost of physician burnout in the United States. Ann Intern Med 2019;170:784-90.

13. Dyrbye LN, Satele D, Shanafelt T. Ability of a 9-item well-being index to identify distress and stratify quality of life in US workers. 7 Occup Environ Med 2016;58:810-7.

14. Jha AK, Iliff AR, Chaoui AA, et al. A crisis in health care: a call to action on physician burnout. Available: www.massmed.org/News-and-Publications/MMS -News-Releases/Physician-Burnout-Report-2018/ (accessed 2020 Feb. 21).

15. Noseworthy J, Madara J, Cosgrove D, et al. Physician burnout is a public health crisis: a message to our fellow health care CEOs. Health Affairs Blog 2017 Mar. 28. doi: 10.1377/hblog20170328.059397.

16. West CP, Dyrbye LN, Shanafelt TD. Physician burnout: contributors, consequences and solutions. F Intern Med 2018;283:516-29.

17. Garcia LC, Shanafelt TD, West CP, et al. Burnout, depression, career satisfaction, and work-life integration by physician race/ethnicity. FAMA Netw Open 2020;3:e2012762.

18. French CE, Ferlie E, Fulop NJ. The international spread of Academic Health Science Centres: a scoping review and the case of policy transfer to England. Health Policy 2014;117:382-91.

19. Maslach C, Schaufeli WB, Leiter MP. Job burnout. Annu Rev Psychol 2001;52: 397-422.

20. Dyrbye LN, Satele D, Sloan J, et al. Utility of a brief screening tool to identify physicians in distress. 7 Gen Intern Med 2013;28:421-7.

21. Valid and reliable survey instruments to measure burnout, well-being, and other work-related dimensions. Washington: National Academy of Medicine; 2018. Available: https://nam.edu/valid-reliable-survey-instruments-measure -burnout-well-work-related-dimensions (accessed 2019 Feb. 7).

22. Dyrbye LN, Johnson PO, Johnson LM, et al. Efficacy of the Well-Being Index to identify distress and well-being in U.S. nurses. Nurs Res 2018;67:447-55.

23. Spreitzer GM. Psychological empowerment in the workplace: dimensions, measurement, and validation. Acad Manage 7 1995;38:1442-65.

24. Shanafelt TD, Dyrbye LN, Sinsky C, et al. Relationship between clerical burden and characteristics of the electronic environment with physician burnout and professional satisfaction. Mayo Clin Proc 2016;91:836-48.
25. Kroth PJ, Morioka-Douglas N, Veres S, et al. The electronic elephant in the room: physicians and the electronic health record. 7AMIA Open 2018;1:49-56.

26. Melnick ER, Dyrbye LN, Sinsky CA, et al. The association between perceived electronic health record usability and professional burnout among US physicians. Mayo Clin Proc 2020;95:476-87.

27. Kroth PJ, Morioka-Douglas N, Veres S, et al. Association of electronic health record design and use factors with clinician stress and burnout. $7 A M A$ Netw Open 2019;2:e199609.

28. CMA National Physician Health Survey: a national snapshot. Ottawa: Canadian Medical Association; 2018. Available: www.cma.ca/sites/default/files/2018-11/ nph-survey-e.pdf (accessed 2020 Mar. 6).

29. Burns KEA, Fox-Robichaud A, Lorens E, et al. Gender differences in career satisfaction, moral distress, and incivility: a national, cross-sectional survey of Canadian critical care physicians. Can 7 Anaesth 2019;66:503-11.

30. Rama-Maceiras P, Jokinen J, Kranke P. Stress and burnout in anaesthesia: a real world problem? Curr Opin Anaesthesiol 2015;28:151-8.

31. Martin D, Miller AP, Quesnel-Vallée A, et al. Canada's universal health-care system: achieving its potential. Lancet 2018;391:1718-35.

32. Occupancy rate of curative (acute) care beds, 2000 and 2015 (or nearest year) [graph]. In: Health at a glance 2017: OECD indicators. Paris: Organisation for Economic Co-operation and Development; 2017.

33. Rubin B, Goldfarb R, Satele D, et al. Burnout and distress among nurses in a cardiovascular centre of a quaternary hospital network: a cross-sectional survey. CMA7 Open 2021;9:19-28.

34. Rubin B, Goldfarb R, Satele D, et al. Burnout and distress among allied health care professionals in a cardiovascular centre of a quaternary hospital network: a cross-sectional survey. CMA7 Open 2021;9:29-37.

35. West CP, Dyrbye LN, Erwin PJ, et al. Interventions to prevent and reduce physician burnout: a systematic review and meta-analysis. Lancet 2016;388:2272-81.

36. Panagioti M, Panagopoulou E, Bower P, et al. Controlled interventions to reduce burnout in physicians: a systematic review and meta-analysis. $7 A M A$ Intern Med 2017;177:195-205.

37. Dyrbye LN, Shanafelt TD, Gill PR, et al. Effect of a professional coaching intervention on the well-being and distress of physicians: a pilot randomized clinical trial. 7AMA Intern Med 2019;179:1406-14.

38. Linzer M, Poplau S, Grossman E, et al. A cluster randomized trial of interventions to improve work conditions and clinician burnout in primary care: results from the Healthy Work Place (HWP) Study. 7 Gen Intern Med 2015;30:1105-11.

Affiliations: Division of Vascular Surgery (Rubin), Peter Munk Cardiac Centre, Toronto General Hospital, University Health Network; Goldfarb Intelligence Marketing (Goldfarb), Toronto, Ont.; Division of Biomedical Statistics and Informatics (Satele), Mayo Foundation for Medical Education and Research, Rochester, Minn.; Office of Professional Practice \& Policy (Graham), Toronto General Hospital, Toronto, Ont.

Contributors: Barry Rubin, Rebecca Goldfarb and Leanna Graham designed the study. Barry Rubin drafted the manuscript. Daniel Satele carried out the statistical analysis. All of the authors contributed to the study conception, analyzed and interpreted the data, revised the manuscript critically for important intellectual content, approved the version to be published and agreed to be accountable for all aspects of the work.

Funding: This work was supported by a grant from the Peter Munk Cardiac Centre Innovation Fund.

Data sharing: All data presented in this manuscript are available to other investigators on request from the corresponding author.

Disclaimer: The funding group had no role in the design, conduct or implementation of the study or manuscript, or the decision to submit, preparation of and editing of the manuscript.

Content licence: This is an Open Access article distributed in accordance with the terms of the Creative Commons Attribution (CC BY-NC-ND 4.0) licence, which permits use, distribution and reproduction in any medium, provided that the original publication is properly cited, the use is noncommercial (i.e., research or educational use), and no modifications or adaptations are made. See: https://creativecommons.org/licenses/by-nc-nd/4.0/.

Acknowledgements: The authors thank Liselotte Dyrbye, Professor of Medical Education and Professor of Medicine, Division of Community Internal Medicine, Department of Internal Medicine, Mayo Clinic and Danielle Martin, Executive Vice President and Chief Medical Executive, Women's College Hospital, for very helpful discussions.

Supplemental information: For reviewer comments and the original submission of this manuscript, please see www.cmajopen.ca/content/9/1/ E10/suppl/DC1. 